\title{
Adsorption of Carbon Dioxide onto Activated Carbon Prepared from Coconut Shells
}

\author{
Pei-Hsing Huang, ${ }^{1}$ Hao-Hsiang Cheng, ${ }^{1}$ and Sheau-Horng Lin ${ }^{2}$ \\ ${ }^{1}$ Department of Mechanical Engineering, National Pingtung University of Science and Technology, Pingtung 912, Taiwan \\ ${ }^{2}$ Department of Wood Science and Design, National Pingtung University of Science and Technology, Pingtung 912, Taiwan \\ Correspondence should be addressed to Pei-Hsing Huang; phh@mail.npust.edu.tw
}

Received 29 October 2014; Revised 15 January 2015; Accepted 5 February 2015

Academic Editor: Grigorios Itskos

Copyright (c) 2015 Pei-Hsing Huang et al. This is an open access article distributed under the Creative Commons Attribution License, which permits unrestricted use, distribution, and reproduction in any medium, provided the original work is properly cited.

\begin{abstract}
This study presents the fabrication of high-quality activated carbon (AC) from discarded coconut shells. The effects of experimental parameters such as activation temperature and activation time on the basic characteristics of AC, including charcoal yield, ash content, $\mathrm{pH}$ value, Brunauer-Emmett-Teller (BET) specific surface area, total pore volume, and iodine adsorption, are investigated. The results indicate that as the activation temperature and activation time increase, the charcoal yield of the AC decreases. In contrast, iodine adsorption, ash content, $\mathrm{pH}$ value, and total pore volume increase with activation temperature. The AC sample activated at $1000^{\circ} \mathrm{C}$ for $120 \mathrm{~min}$ had the highest BET specific surface area and total pore volume and thus the best $\mathrm{CO}_{2}$ adsorption performance. This sample was compared with 30-mesh commercial AC. The results reveal that coconut-based AC has better instantaneous adsorption capabilities.
\end{abstract}

\section{Introduction}

The rapid development of industrial technologies has significantly increased the concentration of greenhouse gases such as $\mathrm{CO}_{2}, \mathrm{CH}_{4}, \mathrm{HFCs}$, and PFCs in the atmosphere. The greenhouse effect of these gases leads to environmental pollution, exacerbates global warming, raises ocean water levels, and affects the balance of the ecosystem. Among greenhouse gases, the greenhouse effect of $\mathrm{CO}_{2}$ has the greatest impact on global warming $[1,2]$. Aggressive efforts are being made to develop technologies to capture $\mathrm{CO}_{2}$ to mitigate the greenhouse effect. In addition, the captured $\mathrm{CO}_{2}$, which is nontoxic and inexpensive, can be used to produce various organic solvents, chemicals, and media materials (such as calcium carbonate, glucose, and starch), and thus it can potentially bring substantial commercial benefits.

Porous carbon-based materials have high thermal and chemical stability as well as good adsorption capabilities $[1,3-8]$. Their low cost and recyclability make them ideal for pollution prevention [9-11]. Gergova and Eser [12] used apricot stones to fabricate activated carbon $(\mathrm{AC})$ and found a low total pore volume $\left(V_{p}\right)$ in AC produced using pyrolysis or incomplete activation. Using formaldehyde resin and chemical and physical activation processes, Teng and Wang [13] created AC with high-density porosity. Scanning electron microscopy (SEM) revealed that physical activation processes produce compounds with a higher Brunauer-Emmett-Teller (BET) specific surface area. Park and Kim [3] fabricated AC using polyacrylonitrile (PAN) carbon fiber fabric and phenolic resin and found that using an activation temperature $\left(T_{\text {activation }}\right)$ of $900^{\circ} \mathrm{C}$ led to the highest BET specific surface area. With activation at $1000^{\circ} \mathrm{C}$, the pores were easily filled in, collapsed, and formed graphite-like carbon structures, all of which decreased the BET specific surface area [3]. With rockrose as the raw material, Pastor-Villegas and DuránValle [14] produced $\mathrm{AC}$ using $\mathrm{CO}_{2}$ and $\mathrm{H}_{2} \mathrm{O}$ activation. They discovered that low-temperature activation processes using $\mathrm{H}_{2} \mathrm{O}$ (particularly at $700^{\circ} \mathrm{C}$ ) generated a higher total pore volume and a larger pore volume than those obtained with any activation process using $\mathrm{CO}_{2}$. Wang et al. [15] employed $\mathrm{H}_{2} \mathrm{O}$ activation to fabricate polystyrene-based AC spheres and found that spherical AC contains a greater volume of narrow micropores, requires higher temperatures for desorption, and has a higher irreversible adsorption capacity. Huang et al. [16] used Chinese fir wood to create AC and found that higher 


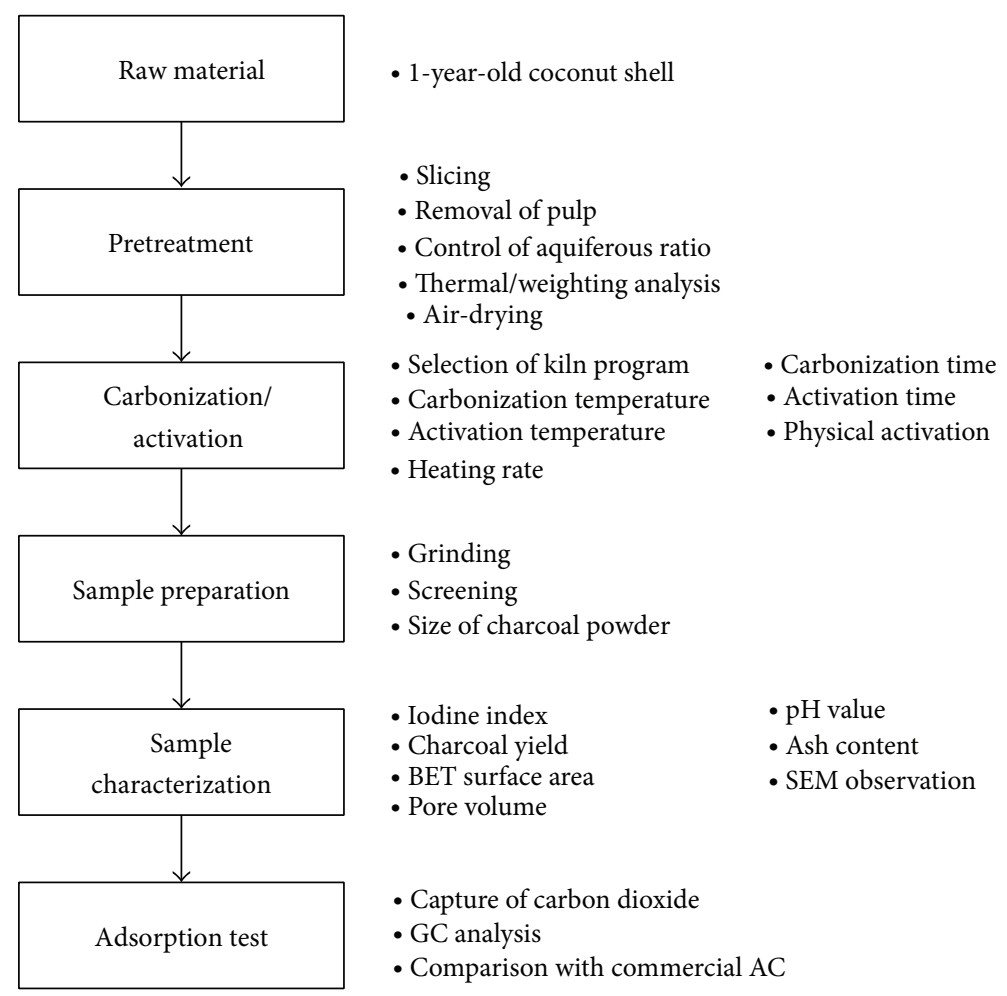

FIgURE 1: Procedure for preparing coconut-shell-based AC.

carbonization temperatures contribute to greater quantities of porous structures and a higher BET specific surface area. Using corncobs to produce AC, Liu et al. [17] established that the activation temperature and precarbonization particle size influence the BET specific surface area and pore size distribution of the AC. Furthermore, the corncob-derived AC was found to be effective in hydrogen adsorption.

Since coconut shell carbonaceous adsorbents possess high BET specific surface area and porosity [18], we used discarded coconut shells to produce AC. This work examines the technical feasibility of producing AC from coconut shell wastes. The properties of coconut shell AC and the effects of processing parameters on the $\mathrm{CO}_{2}$ adsorption capabilities are also discussed.

\section{Materials and Methods}

2.1. Sample Preparation. We used rope coconuts grown in Taiwan to produce AC, the powder of which was subjected to adsorption experiments. The high and unevenly distributed water content in coconuts makes carbonization and activation temperatures difficult to control, which affects the quality of the AC. For this reason, we performed a pretreatment that involved cutting open the coconuts, removing all of the coconut pulp and some of the fibers, and air-drying the remaining shell. For uniform quality in carbonization and activation, the water content of the shells was maintained at between $13 \%$ and $16 \%$. The dried shells were cut into pieces with dimensions of $5 \mathrm{~cm}$ (length) $\times 4 \mathrm{~cm}$ (width) $\times$ $2 \sim 3 \mathrm{~cm}$ (thickness) and placed in a high-temperature kiln for carbonization.
2.2. Induction Heater. A compact charcoal kiln was used to produce coconut shell AC. Its maximum capacity is about $1 \mathrm{~kg}$ of raw materials per batch. Induction heaters, which incorporate a coil directly fed from the electricity supply, were installed in the kiln walls for generating heat energy to carbonize coconut shells. Temperature sensors were placed inside the charcoal kiln for monitoring the carbonization temperature. The carbonization temperature was controlled by setting the temperature of the pyrolysis process. Inert gas $\left(\mathrm{N}_{2}\right)$ was pumped into the kiln at $10 \mathrm{~mL} / \mathrm{min}$ to prevent the coconut shells from coming into contact with air during carbonization and activation. During carbonization, the temperature was increased at $15^{\circ} \mathrm{C} / \mathrm{min}$ to $500^{\circ} \mathrm{C}$ and held for $60 \mathrm{~min}$. Following the activation process, steam, the activation fluid, was immediately pumped into the furnace at $3 \mathrm{~mL} / \mathrm{min}$. Five activation temperatures $(600,700,800,900$, and $1000^{\circ} \mathrm{C}$ ) and two activation times (60 and $120 \mathrm{~min}$ ) were adopted for comparing the quality of coconut-shell-based AC. Subsequently, the heater and gas flow were turned off and the carbonized coconut shell AC was allowed to cool naturally inside the kiln to room temperature. Finally, the shells were ground into powder (30 mesh). We used a $\mathrm{CO}_{2}$ adsorption apparatus to evaluate the $\mathrm{CO}_{2}$ adsorption capacities of the samples and compared the results with those of commercially available AC. Figure 1 shows the framework of the procedure for preparing coconut-shell-based AC.

2.3. $\mathrm{CO}_{2}$ Adsorption Test Procedure. Figure 2 shows the structure of the $\mathrm{CO}_{2}$ adsorption apparatus. The procedure for testing $\mathrm{CO}_{2}$ adsorption is as follows. 


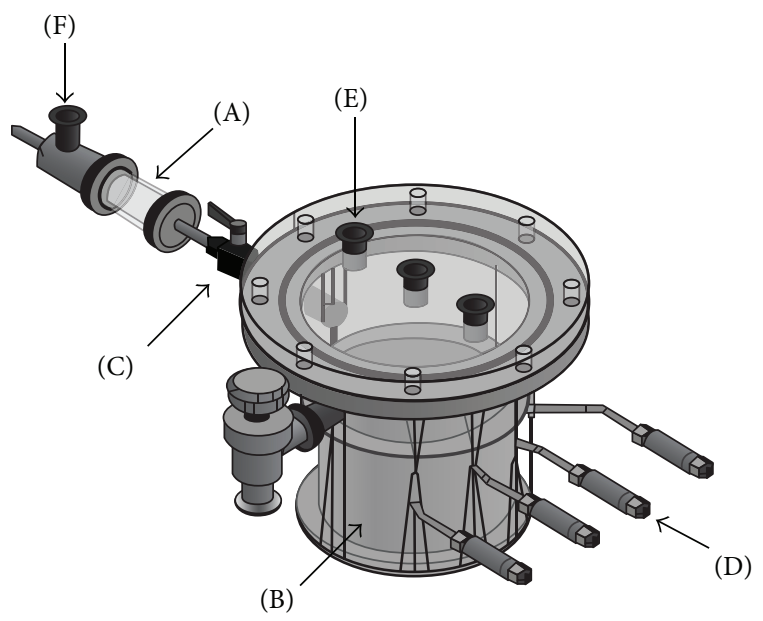

FIGURE 2: Structure of $\mathrm{CO}_{2}$ adsorption apparatus: (A) sample case, (B) gas mixing chamber, (C) ball valve, (D) inlet, (E) preadsorption sampling hole, and (F) postadsorption sampling hole.

(1) First, $200 \mathrm{~g}$ (30 mesh) of the coconut-shell-based AC is placed into the sample case (A), and the vacuum pump is turned on to draw air from the gas mixing chamber (B) until it becomes a vacuum.

(2) The ball valve $(\mathrm{C})$ is then closed, and $\mathrm{CO}_{2}$ is pumped in through the inlet (D). Preadsorption sampling is conducted at the sampling hole (E) to confirm that the $\mathrm{CO}_{2}$ in the chamber has reached a concentration of $100 \%$ at a pressure of $40 \mathrm{cmHg}$.

(3) The vacuum pump is turned on and the ball valve (C) is opened. With the outflow to the vacuum pump and the gas inflow controlled at equal flow rates, postadsorption sampling can be performed at the sampling hole $(\mathrm{F})$ to extract the $\mathrm{CO}_{2}$ gas following adsorption by the AC for gas chromatography (GC) testing.

(4) The influence of the various $\mathrm{AC}$ samples on the $\mathrm{CO}_{2}$ concentration can be observed from the GC tests and Quick Chrom graphs, from which the $\mathrm{CO}_{2}$ concentration can be obtained.

\subsection{Method for Determining $\mathrm{CO}_{2}$ Adsorption Capacity}

(1) $200 \mathrm{~g}$ of AC is placed into the sample case (A), and the vacuum pump is turned on to draw air from the gas mixing chamber (B). When it becomes a vacuum, the pump is turned off.

(2) Then, $\mathrm{CO}_{2}$ is pumped in through the inlet (D), and preadsorption sampling is conducted at the sampling hole (E), as shown in Figure 2, to confirm that the $\mathrm{CO}_{2}$ in the chamber has reached a concentration of $100 \%$ at a pressure of $40 \mathrm{cmHg}$. Then, the gas inflow is stopped.

(3) The density of $\mathrm{CO}_{2}$ under atmospheric pressure $(76 \mathrm{cmHg})$ is $1.96 \mathrm{~g} / \mathrm{L}$. We can therefore calculate that, at $40 \mathrm{cmHg}$ in the $\mathrm{CO}_{2}$ adsorption analyzer, the initial concentration before adsorption is $M_{1}=$ $1031.548 \mathrm{mg} / \mathrm{L}$.

(4) As shown in Figure 2, a preadsorption sample is taken from the sampling hole (E) and then injected into the gas chromatograph, which produces a peak graph that provides $L_{1}$.

(5) The vacuum pump is then turned on and the ball valve (C) opened at the same time. The gas flow rate is kept constant $(600 \mathrm{~mL} / \mathrm{min})$ so that the $\mathrm{CO}_{2}$ concentration in the gas mixing chamber (B) remains the same. As shown in Figure 2, a postadsorption sample can be taken from the sampling hole $(\mathrm{F})$ and injected into the gas chromatograph, which produces a peak graph that provides $L_{2}$. Using (1), the postadsorption $\mathrm{CO}_{2}$ concentration $\left(\mathrm{M}_{2}\right)$ at the sampling hole $(\mathrm{F})$ can be calculated.

(6) The difference between the $\mathrm{CO}_{2}$ concentrations before and after the AC filter material $\left(\Delta M_{\mathrm{CO}_{2}}\right)$ can be derived using (2).

(7) We recorded the variations in the concentration difference $\left(\Delta M_{\mathrm{CO}_{2}}\right)$ at $t=1,10,20$, and $30 \mathrm{~min}$ to examine the $\mathrm{CO}_{2}$ adsorption performance of the $\mathrm{AC}$ filter materials. Consider

$$
\frac{L_{2}}{L_{1}}=\frac{M_{2}}{M_{1}},
$$

where $M_{1}$ is $\mathrm{CO}_{2}$ concentration at $\mathrm{B}$ (initial $\mathrm{CO}_{2}$ concentration before adsorption), $M_{2}$ is $\mathrm{CO}_{2}$ concentration at $\mathrm{F}$ (initial $\mathrm{CO}_{2}$ concentration after adsorption), $L_{1}$ is relative height in peak graph from Quick Chrom (initial $\mathrm{CO}_{2}$ concentration before adsorption), and $L_{2}$ is relative height in peak graph from Quick Chrom (initial $\mathrm{CO}_{2}$ concentration after adsorption). Consider

$$
\Delta M_{\mathrm{CO}_{2}}=M_{1}-M_{2},
$$

where $\Delta M_{\mathrm{CO}_{2}}$ is difference in $\mathrm{CO}_{2}$ concentration before and after adsorption.

2.5. Gas Chromatography Analysis. The $\mathrm{CO}_{2}$ adsorption capacities of the AC powders were analyzed using GC (Shimadzu GC-8A). GC is one of the most commonly used tools for analyzing volatile and semivolatile organic compounds. We gasified the test samples and pumped them through a column for separation using helium flowing at $40 \mathrm{~mL} / \mathrm{min}$ as a carrier gas. We filled the column with a solid-phase carrier, which has a liquid film on the surface. As a sample passes this film, the speed at which any compound moves in the column is determined by the net value of the two opposing forces, which varies depending on the compound. The speed differences thus separate the compounds. The adsorption concentration $(M)$ can be derived from the geometric ratio of the relative heights $(L)$ in the peak graphs produced by the GC analysis program Quick Chrom.

2.6. Determination of Charcoal Yield. The charcoal yield, $Y_{\text {char }}(\%)$, produced by a kiln is given by $Y_{\text {char }}=m_{\text {char }} / m_{\text {raw }}$, 
where $m_{\text {char }}$ is the dry mass of charcoal taken from the kiln and $m_{\text {raw }}$ is the dry mass of the raw coconut shells loaded into the kiln [19].

2.7. Determination of Ash Content and $\mathrm{pH}$ Value. The ash content of coconut shell AC was determined according to CNS 5581 [20], which involved heating the carbonized charcoal in an open crucible (type: L3C6, Chuanhua Precision Co., Germany) to $800 \pm 25^{\circ} \mathrm{C}$ and holding at this temperature for $3 \mathrm{~h}$. The material that remains in the crucible is defined as ash; that is, ash content $(\%)=100 \times m_{\text {ash }} / m_{\text {char }}$, where $m_{\text {char }}$ is the initial dry mass of charcoal and $m_{\text {ash }}$ is the dry mass of ash that remains following combustion of the carbonized charcoal [19]. In this work, the $\mathrm{pH}$ value was measured according to CNS 697-698 [21] using a Eutech meter ( $\mathrm{pH} 700$, USA).

2.8. Scanning Electron Microscopy Observation. SEM (Philips, CM-200, Japan) was used to analyze the microporous structures of coconut shell AC. SEM was operated at $15 \mathrm{kV}$ in secondary electron imaging mode.

2.9. Iodine Adsorption Value. The iodine value of the coconut shell AC was determined according to ASTM D4607-94 [22], which is based on a three-point adsorption isotherm. The iodine adsorbed per gram of coconut shell AC at a residual iodine concentration of $0.02 \mathrm{~N}$ is reported as the iodine value; that is, iodine value $(\mathrm{mg} / \mathrm{g})=[A-(\mathrm{DF}) \cdot(B) \cdot(S)] / M$, where $A$ and $B$ are 12693.0 and 126.93 , respectively, DF represents the dilution factor, $S$ is the volume (in $\mathrm{mL}$ ) of standard sodium thiosulphate solution, and $M$ denotes the coconut shell AC used (in g) $[19,22]$.

\subsection{Measurement of Pore Volume and BET Specific Surface} Area. Surface area and porosity are two important physical properties that determine the quality and effectiveness of coconut shell AC. In this work, the multipoint (12-point) BET method and the Langmuir method were used to determine the BET specific surface area and adsorption isotherms of nitrogen at 77.3 K using an ASAP 2010 apparatus.

\section{Results and Discussion}

SEM was used to analyze the microporous structures of coconut-shell-based AC, including the cross-sectional parenchyma cells, thecal pores, and cell walls. Figure 3 shows SEM images of the parenchyma cells and cell wall pores in the AC samples. Figures 3(a)-3(e) show the AC samples activated at $600,700,800,900$, and $1000^{\circ} \mathrm{C}$, respectively. As shown, the majority of mesopores and micropores were concealed within the macropores, extending layer upon layer. This indicates that the AC had multisized porosity. A comparison of Figures 3(a)-3(e) reveals that as the activation temperature increased, the number of smaller pores in the large pores increased, whereas the number of clogged pores on the surface decreased. This demonstrates that activation removes hydrocarbons and tar, which enhances the adsorption capacity of the AC.
To reduce experimental error, the adsorption characteristics and properties are measured from three different coconut shell AC samples prepared at each activation temperature. The mean values and associated standard errors calculated from the measured raw data are presented in the following figures. Figure 4 shows the averages of charcoal yield, ranging from $20.4 \%$ to $34.6 \%$. As shown, due to the pyrolysis and vaporization of hydrocarbons and tar within the AC, charcoal yield declined with increasing activation temperature and activation time. The experimental results are consistent with those reported by Wang et al. [23]. Generally, the main elemental constituents of biomass minerals are $\mathrm{K}, \mathrm{Na}, \mathrm{Ca}$, $\mathrm{Mg}$, and $\mathrm{Si}$, with smaller amounts of $\mathrm{S}, \mathrm{P}, \mathrm{Fe}, \mathrm{Mn}$, and Al [24, 25]. These inorganic constituents occur as oxides, silicates, carbonates, sulfates, chlorides, and phosphates [25]. Inorganic substances are rarely volatilized during activation, remaining in the ash and thereby increasing the ash content. Figure 5 shows the ash content for various activation temperatures and activation times, ranging between $2.9 \%$ and $3.31 \%$. These values conform to the practical limit for the level of ash content allowed in commercial AC (2 to 5\%) [26]. The inorganic salts in ash generally possess a high fusion point and largely remain after the water and organic matter have been removed at elevated temperatures. The ash content thus increases with activation temperature and activation time.

The $\mathrm{pH}$ value was measured according to CNS 697-698 [21] using a Eutech meter ( $\mathrm{pH} 700$, USA). As shown in Figure 6 , the $\mathrm{pH}$ value increases with activation temperature and activation time. This is attributed to the burning of calcite and the production of lime during the high-temperature pyrolysis steps. Moreover, the activation process increased the surface area and porosity, as well as the surface basicity of AC [27]. As shown, the increase in $\mathrm{pH}$ value is most significant between $600^{\circ} \mathrm{C}$ and $800^{\circ} \mathrm{C}$, after which the rate of increase declines. Among the AC samples derived from coconut shells, the one activated at $1000^{\circ} \mathrm{C}$ for $120 \mathrm{~min}$ displayed the highest $\mathrm{pH}$ value (9.84). The values correspond to the commercial specifications of coconut-shell-based AC ( $\mathrm{pH}$ 9-11) [26].

During carbonization, the hydrocarbons attached to the coke structures can often clog up the pores. Increasing the activation temperature and activation time can promote the removal of more hydrocarbons and impurities and increase the total pore volume and BET specific surface area. As shown in Figure 7, the BET specific surface area increases with activation temperature, with the most significant increase being between $600^{\circ} \mathrm{C}$ and $800^{\circ} \mathrm{C}$. When the activation temperature exceeds $800^{\circ} \mathrm{C}$, the effect of activation temperature on BET specific surface area gradually weakens. This can be attributed to high activation temperatures allowing easier removal of organic matter, formation of more micropores, and an increase in specific surface area, but also easier collapse of micropores, backfilling, and formation of graphitelike carbon structures, thus decreasing the BET specific surface area [3]. Moreover, the BET specific surface area increased with activation time, with the sample activated at $1000^{\circ} \mathrm{C}$ for $120 \mathrm{~min}$ having the highest BET specific surface area $\left(824 \mathrm{~m}^{2} / \mathrm{g}\right)$. Figure 8 presents the negative correlation between BET specific surface area and charcoal yield, which 

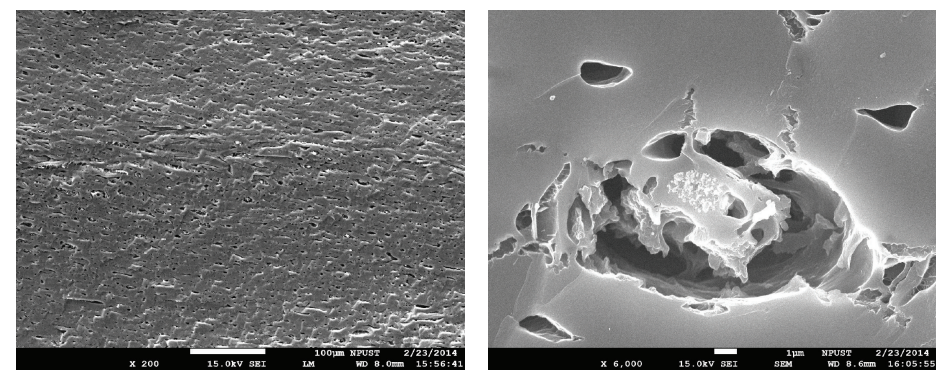

(a)
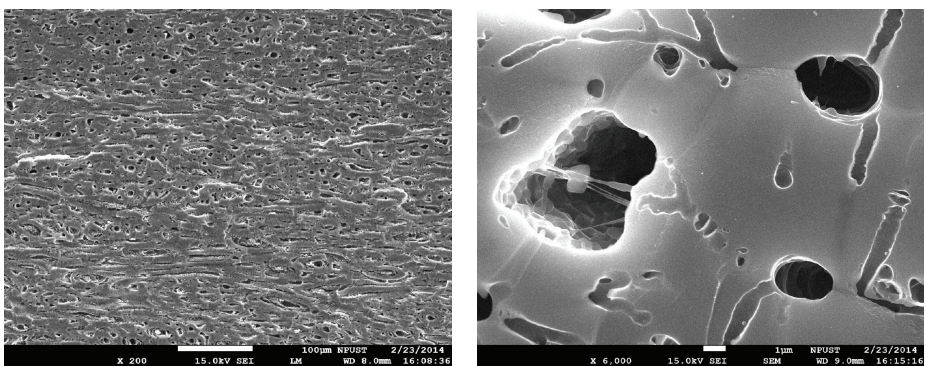

(b)
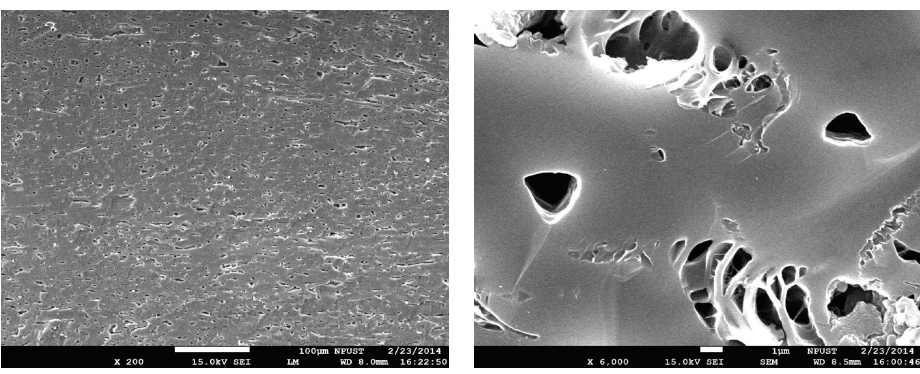

(c)
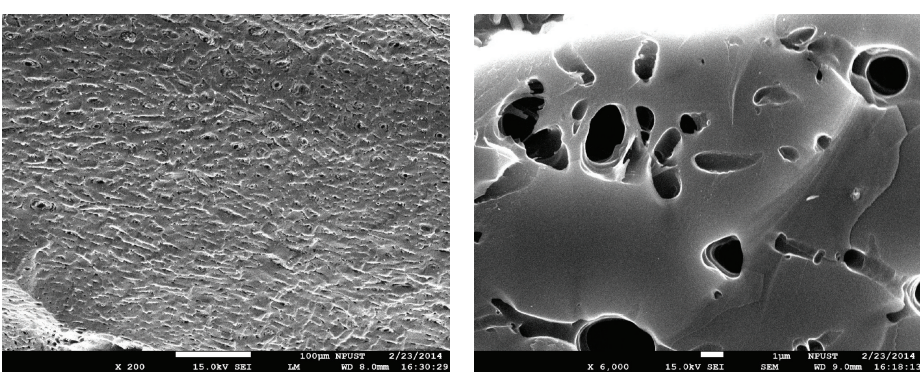

(d)


(e)

FIGURE 3: SEM images (left) and magnified views (right) of pore structures of $\mathrm{AC}$ samples activated at (a) $600^{\circ} \mathrm{C},(\mathrm{b}) 700^{\circ} \mathrm{C},(\mathrm{c}) 800^{\circ} \mathrm{C},(\mathrm{d})$ $900^{\circ} \mathrm{C}$, and (e) $1000^{\circ} \mathrm{C}$. 


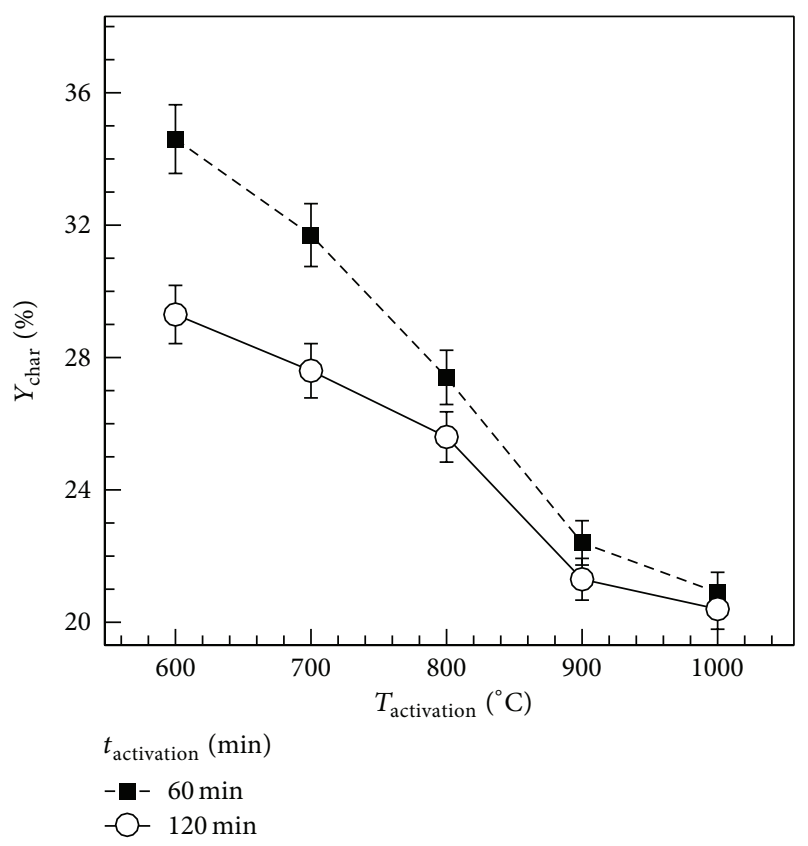

FIGURE 4: Variations in charcoal yield with activation temperature and activation time.



FIGURE 5: Variations in ash content with activation temperature and activation time.

occurs on account of the fact that high activation temperatures allow easier release of volatile substances and tar in the carbon powder, which form micropores, increasing BET specific surface area and reducing charcoal yield.

The formation of pores and changes to the pore structure in AC mostly occur during the activation process. As the activation temperature increases, the hemicellulose, cellulose,

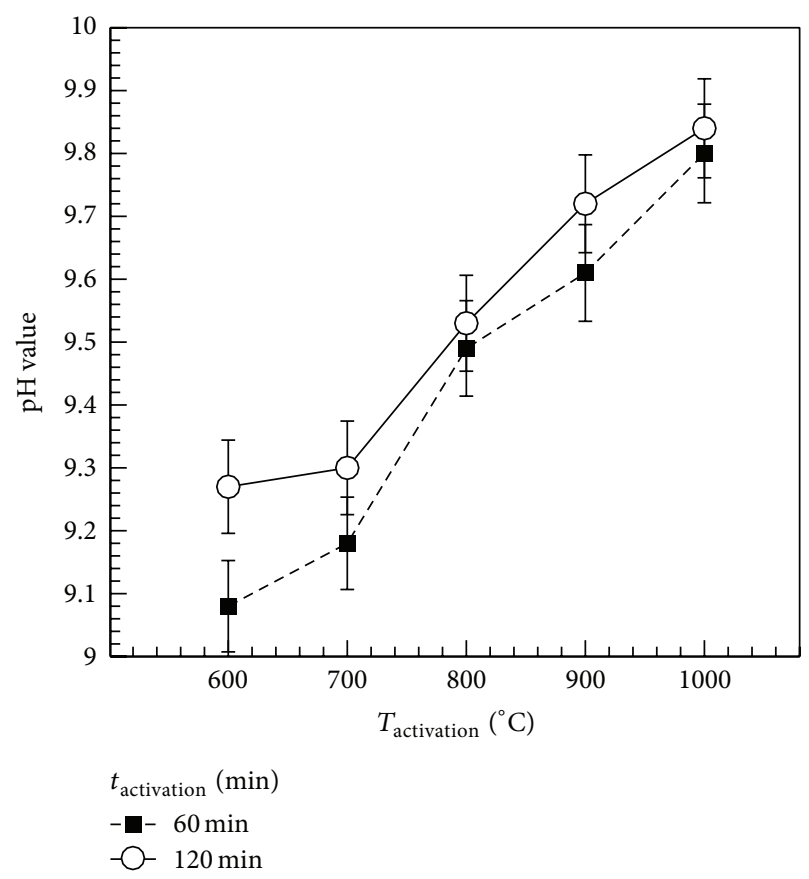

FIgURE 6: Variations in $\mathrm{pH}$ value with activation temperature and activation time.

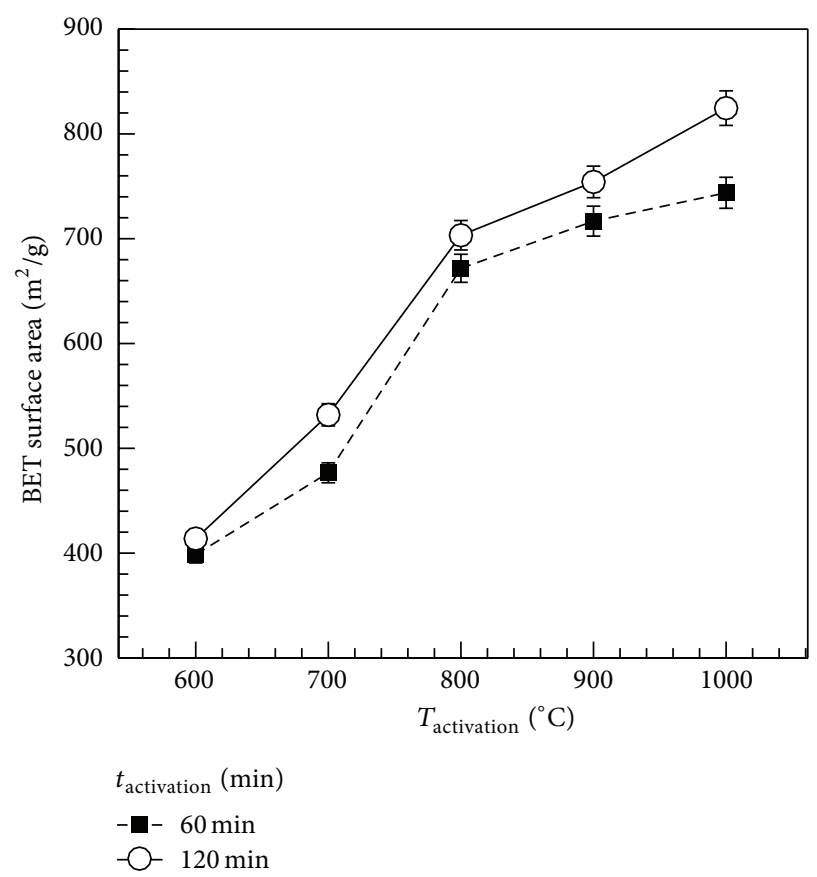

FIGURE 7: BET surface area as a function of activation temperature and activation time.

and lignin in the coconut shells undergo pyrolysis. The residual carbon molecules reaggregate into coke structures and form numerous micropores. Therefore, higher activation temperatures expedite pyrolysis reactions. Furthermore, as heat and water vapor travel via diffusion and thermal transfer, longer activation periods facilitate the diffusion 




FIGURE 8: Relationship between charcoal yield and BET specific surface area.

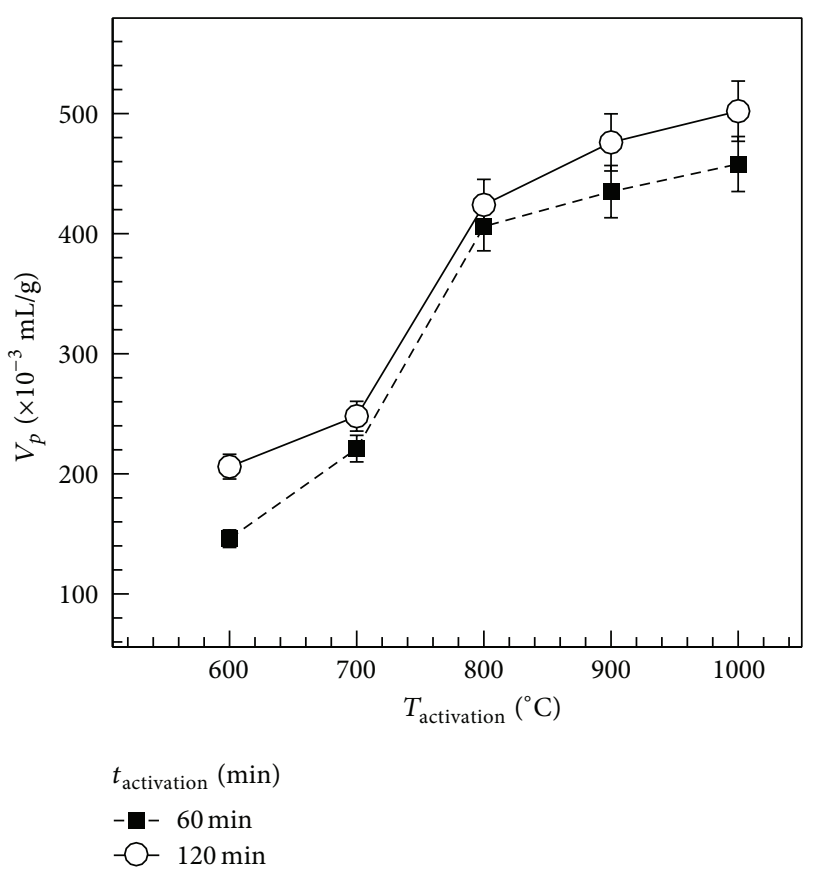

FIGURE 9: Total pore volume as a function of activation temperature and activation time.

of heated water molecules within AC, which then activate more carbon molecules and generate a greater quantity of pores. As shown in Figure 9, total pore volume increases with activation temperature and activation time. Thus, the sample activated at $1000^{\circ} \mathrm{C}$ for $120 \mathrm{~min}$ showed the highest total pore volume $\left(V_{p}=0.502 \mathrm{~mL} / \mathrm{g}\right)$. The results are superior to those for the AC produced by Achaw and Afrane [28] with a carbonization temperature of $325^{\circ} \mathrm{C}$, activation temperature of $800^{\circ} \mathrm{C}$, and activation time of $120 \mathrm{~min}$ (BET specific surface area $=524.5 \mathrm{~m}^{2} / \mathrm{g}$; total pore volume $\left.V_{P}=0.266 \mathrm{~cm}^{3} / \mathrm{g}\right)$. We speculate that this was because Achaw and Afrane employed a lower carbonization temperature, which caused fewer volatile substances and less tar to be released, and produced underdeveloped coke structures. Using a carbonization temperature of $500^{\circ} \mathrm{C}$, activation temperature of $900^{\circ} \mathrm{C}$, and activation time of $30 \mathrm{~min}$, Azevedoa et al. [29] produced AC with a BET specific surface area of $1,266 \mathrm{~m}^{2} / \mathrm{g}$ and a total pore volume of $0.731 \mathrm{~cm}^{3} / \mathrm{g}$, which are significantly higher than the values in this study. We speculate that this was due to the $\mathrm{ZnCl}_{2}$ added by Azevedoa et al. to the process as an activating agent. This chemical activation increased the BET specific surface area and total pore volume but produced hazardous gases such as $\mathrm{Cl}$ and $\mathrm{HCl}$.

Small pores are adept at adsorbing iodine molecules, and, thus, the quantity of iodine molecules adsorbed is often considered an indicator of the number of micropores in $\mathrm{AC}$ [30-32]. As the temperature rises during activation, endothermic reactions between carbon atoms and water vapor are more likely to occur, which produce numerous macropores, mesopores, and micropores. As the activation time increases, water vapor molecules are more able to infiltrate the inner structure of AC. In this work, the iodine adsorption value of coconut-shell-based AC was determined according to ASTM D4607-94 [22], which is based on a threepoint adsorption isotherm. As shown in Figure 10, increases in activation temperature and activation time facilitate iodine adsorption, and, at certain temperatures, increasing the activation time has a greater impact on the increase in micropores than does increasing the activation temperature. At activation temperatures of over $700^{\circ} \mathrm{C}$, increasing the activation time significantly promotes micropore formation in the AC. 


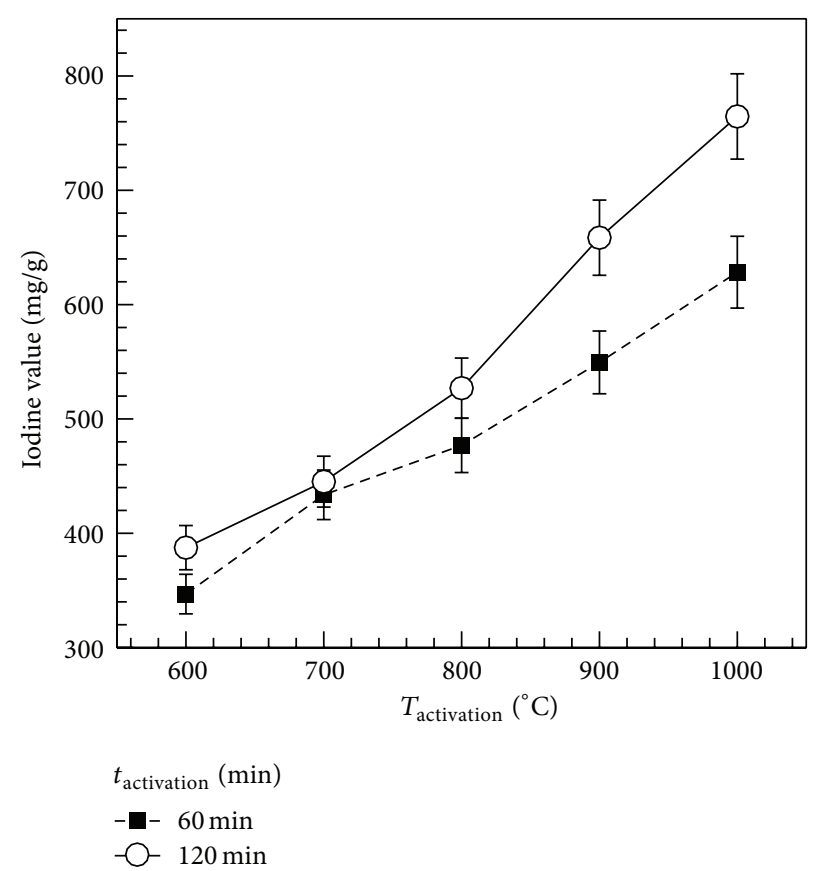

FIGURE 10: Iodine adsorption quantity as a function of activation temperature and activation time.

To determine the adsorption performance of the AC samples derived from coconut shells, we used the vacuum pump in the $\mathrm{CO}_{2}$ adsorption analyzer (see Figure 2) to force $\mathrm{CO}_{2}$ through the AC samples. $\mathrm{GC}$ was used to analyze the concentration changes of $\mathrm{CO}_{2}$ before and after adsorption to identify the $\mathrm{CO}_{2}$ capture capacity of the AC samples. Figure 11 shows the change in $\mathrm{CO}_{2}$ concentration $\left(\Delta M_{\mathrm{CO}_{2}}\right)$ for various $\mathrm{AC}$ samples at different adsorption times $\left(t_{\text {adsorption }}=1,10,20\right.$, and $\left.30 \mathrm{~min}\right)$. As shown in Figures 11(a) and 11(b), $\mathrm{CO}_{2}$ adsorption performance improves with activation time and activation temperature. In Figure 11(b), the sample activated at $T_{\text {activation }}=1000^{\circ} \mathrm{C}$ for $t_{\text {activation }}=$ 120 min showed the best instantaneous adsorption capacity of $\Delta M_{\mathrm{CO}_{2}}=14.40 \mathrm{mg} / \mathrm{L}$ at $t_{\text {adsorption }}=1 \mathrm{~min}$, which is significantly higher than the $12.94 \mathrm{mg} / \mathrm{L}$ for the sample activated at $T_{\text {activation }}=1000^{\circ} \mathrm{C}$ for $t_{\text {activation }}=60 \mathrm{~min}$ in Figure $11(\mathrm{a})$. The reason for this is closely associated with micropore volume and BET specific surface area [33]. At room temperature, the adsorption capacity of $\mathrm{AC}$ increases with the number of available adsorption sites on the adsorbent. Extremely small in size, $\mathrm{CO}_{2}$ molecules are easily captured by micropores. Thus, AC with more micropores and a higher BET specific surface area can adsorb more $\mathrm{CO}_{2}$. As the adsorption time increases, the adsorption performance gradually declines, meaning that the pores are being filled with $\mathrm{CO}_{2}$ molecules and that adsorption saturation is imminent.

To understand the adsorption characteristics of the AC derived from coconut shells, we compared the sample activated at $T_{\text {activation }}=1000^{\circ} \mathrm{C}$ for $t_{\text {activation }}=120 \mathrm{~min}$ with a commercially available AC with similar specifications (BET specific surface area $=800 \mathrm{~m}^{2} / \mathrm{g}$; ash content $=3.0 \%$ ). Prior to the test, we ground the AC powders to 30 mesh and tested the $\mathrm{CO}_{2}$ adsorption capacity of these two samples of equal weight $(200 \mathrm{~g})$. As shown in Figure 12, soon after adsorption began $\left(t_{\text {adsorption }}=1 \mathrm{~min}\right)$, the coconut $\mathrm{AC}$ and the commercial AC reduced the $\mathrm{CO}_{2}$ concentration by 14.3 and $13.2 \mathrm{mg} / \mathrm{L}$, respectively, which demonstrates that the coconut $\mathrm{AC}$ has a higher instantaneous adsorption capacity than that of the commercial AC. The adsorption capabilities of the two powders decrease with time. Following forced adsorption for $30 \mathrm{~min}$, the adsorption capabilities of the two powders dropped to 1.9 and $1.7 \mathrm{mg} / \mathrm{L}$, respectively.

\section{Conclusion}

We prepared various AC samples from coconut shells with various activation temperatures and activation times. The effects of processing parameters on the charcoal yield, ash content, $\mathrm{pH}$ value, BET specific surface area, total pore volume, and iodine adsorption of the $\mathrm{AC}$ were examined. The experimental results indicate that increasing the activation temperature and activation time increases the ash content and $\mathrm{pH}$ value of the $\mathrm{AC}$ but reduces the charcoal yield. The coconut-shell-based AC activated at $T_{\text {activation }}=1000^{\circ} \mathrm{C}$ for $t_{\text {activation }}=120 \mathrm{~min}$ showed the highest $\mathrm{BET}$ specific surface area and total pore volume $\left(824 \mathrm{~m}^{2} / \mathrm{g}\right.$ and $0.502 \mathrm{~mL} / \mathrm{g}$, resp.). The higher activation temperature contributed to the removal of more hydrocarbons and therefore increased the BET specific surface area and total pore volume. However, the high activation temperature also resulted in a significant decrease of charcoal yield. Moreover, increasing the activation time increased BET specific surface area and total pore volume, thereby improving the $\mathrm{CO}_{2}$ adsorption capacity of coconut shell AC. Experiments show that the coconut shell AC has a higher instantaneous adsorption capacity than that of a commercial AC. These results suggest that coconut shell 


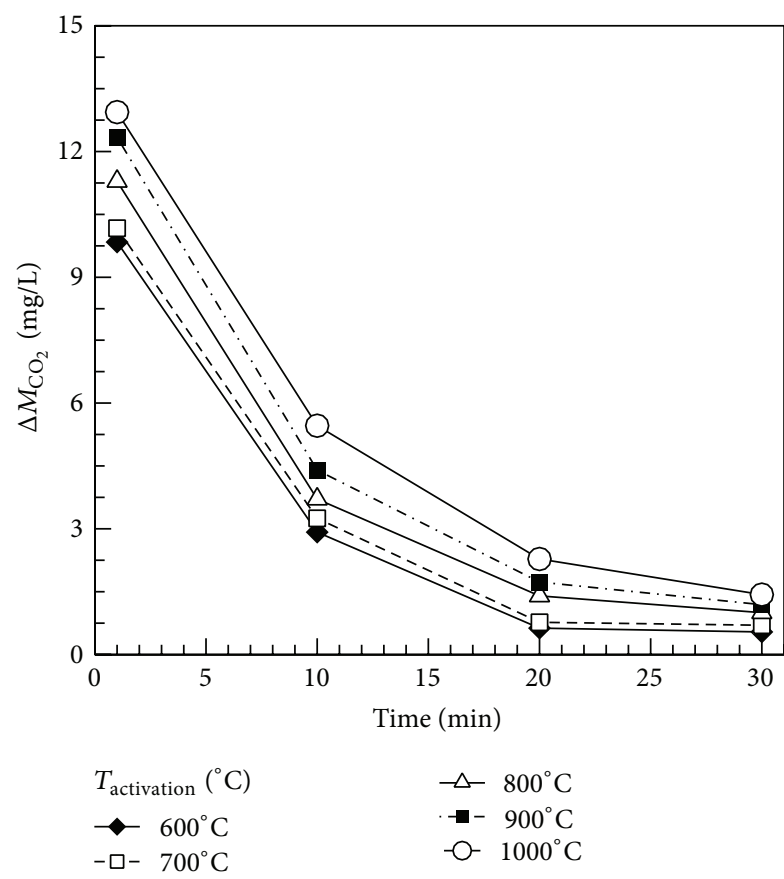

(a)

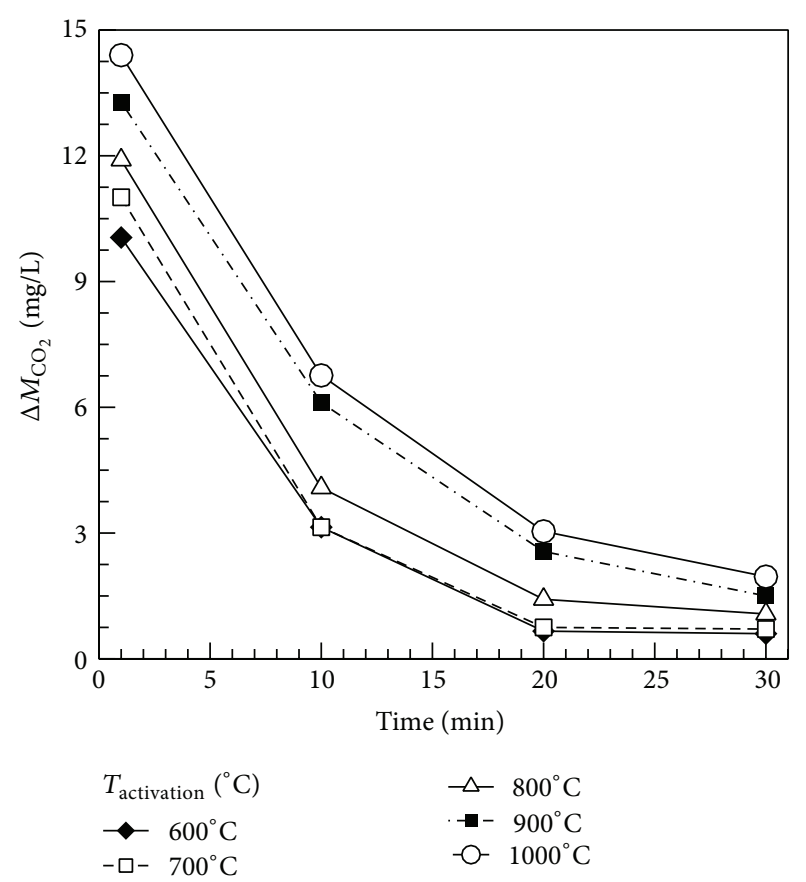

(b)

FIGURE 11: Changes in $\mathrm{CO}_{2}$ concentration $\left(\Delta \mathrm{M}_{\mathrm{CO}_{2}}\right)$ measured after various adsorption times at various activation temperatures $\left(600 \sim 1000^{\circ} \mathrm{C}\right)$ and activation times of (a) $60 \mathrm{~min}$ and (b) $120 \mathrm{~min}$.

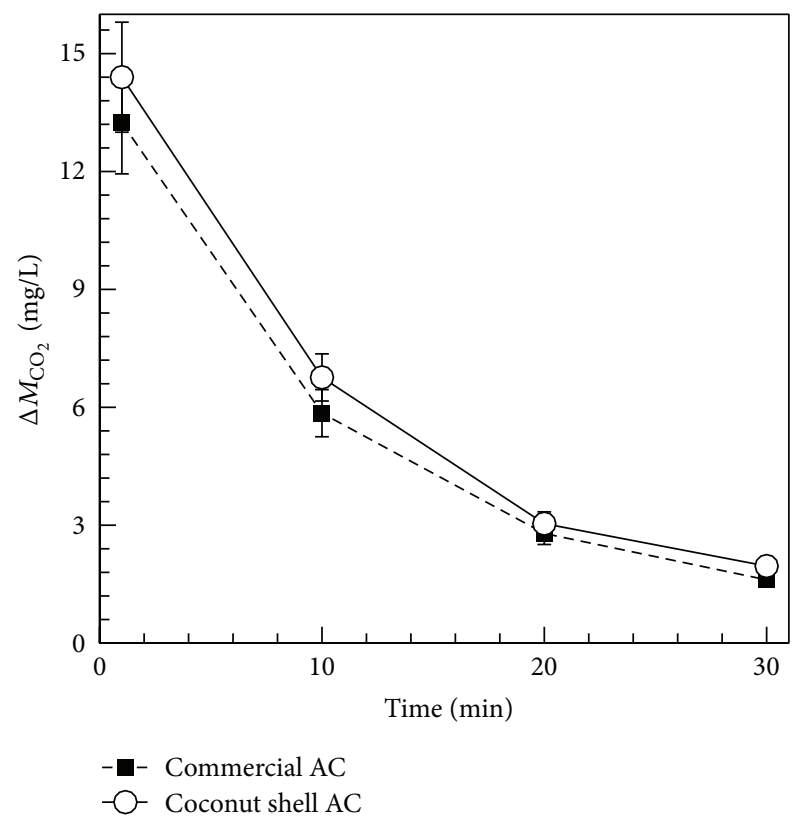

FIGURE 12: Comparison of $\mathrm{CO}_{2}$ adsorption capacity in commercial $\mathrm{AC}$ and coconut $\mathrm{AC}$ at $T_{\text {activation }}=1000^{\circ} \mathrm{C}$ for $t_{\text {activation }}=120 \mathrm{~min}$.

waste is promising for producing high-quality $\mathrm{AC}$ via the regulation of process parameters.

\section{Conflict of Interests}

The authors declare that there is no conflict of interests regarding the publication of this paper.

\section{Acknowledgment}

The authors acknowledge the Ministry of Science and Technology of Taiwan for financially supporting this research under Grant MOST 103-2622-E-020-004-CC3.

\section{References}

[1] J. D. Figueroa, T. Fout, S. Plasynski, H. McIlvried, and R. D. Srivastava, "Advances in $\mathrm{CO}_{2}$ capture technology-The U.S. Department of Energy's Carbon Sequestration Program," International Journal of Greenhouse Gas Control, vol. 2, no. 1, pp. 920, 2008.

[2] H. Yang, Z. Xu, M. Fan et al., "Progress in carbon dioxide separation and capture: a review," Journal of Environmental Sciences, vol. 20, no. 1, pp. 14-27, 2008.

[3] S.-J. Park and K.-D. Kim, "Influence of activation temperature on adsorption characteristics of activated carbon fiber composites," Carbon, vol. 39, no. 11, pp. 1741-1746, 2001.

[4] Y. F. Li, J. Lin, Y. Z. Liu, and H. X. Xing, "Research advances in activated carbon with high specific surface area," Chinese Journal of Tropical Crops, vol. 29, pp. 396-402, 2008.

[5] P.-H. Huang, S.-C. Hung, and M.-Y. Huang, "Molecular dynamics investigations of liquid-vapor interaction and adsorption of formaldehyde, oxocarbons, and water in graphitic slit pores," Physical Chemistry Chemical Physics, vol. 16, no. 29, pp. 1528915298, 2014.

[6] Y.-L. Wang, S.-W. Zhang, W. Du, and W. Wang, "Preparation of pitch-based activated carbons," New Carbon Materials, vol. 21, no. 4, pp. 369-373, 2006.

[7] M. Belhachemi, M. Jeguirim, L. Limousy, and F. Addoun, "Comparison of $\mathrm{NO}_{2}$ removal using date pits activated carbon and modified commercialized activated carbon via different 
preparation methods: effect of porosity and surface chemistry," Chemical Engineering Journal, vol. 253, pp. 121-129, 2014.

[8] P. H. Huang and J. T. Wen, "Study on thorny bamboo activated carbon for capturing heavy metals in groundwater," Applied Mechanics and Materials, vol. 535, pp. 427-431, 2014.

[9] Z. H. Chen, S. B. Deng, H. R. Wei, B. Wang, J. Huang, and G. Yu, "Activated carbons and amine-modified materials for carbon dioxide capture-a review," Frontiers of Environmental Science and Engineering, vol. 7, no. 3, pp. 326-340, 2013.

[10] K. Y. Foo and B. H. Hameed, "An overview of landfill leachate treatment via activated carbon adsorption process," Journal of Hazardous Materials, vol. 171, no. 1-3, pp. 54-60, 2009.

[11] P. Nowicki, H. Wachowska, and R. Pietrzak, "Active carbons prepared by chemical activation of plum stones and their application in removal of $\mathrm{NO}_{2}$," Journal of Hazardous Materials, vol. 181, no. 1-3, pp. 1088-1094, 2010.

[12] K. Gergova and S. Eser, "Effects of activation method on the pore structure of activated carbons from apricot stones," Carbon, vol. 34, no. 7, pp. 879-888, 1996.

[13] H. Teng and S.-C. Wang, "Preparation of porous carbons from phenol-formaldehyde resins with chemical and physical activation," Carbon, vol. 38, no. 6, pp. 817-824, 2000.

[14] J. Pastor-Villegas and C. J. Durán-Valle, "Pore structure of activated carbons prepared by carbon dioxide and steam activation at different temperatures from extracted rockrose," Carbon, vol. 40, no. 3, pp. 397-402, 2002.

[15] Q. Wang, X.-Y. Liang, R. Zhang et al., "Preparation of polystyrene-based activated carbon spheres and their adsorption of dibenzothiophene," New Carbon Materials, vol. 24, no. 1, pp. 55-60, 2009.

[16] B. Huang, X.-R. Chen, M.-S. Jiang, X.-P. Tang, and S.-Y. Gao, "Effect of carbonization temperature on microporous structure of charcoal from Chinese fir wood," Chemistry and Industry of Forest Products, vol. 26, no. 1, pp. 70-74, 2006.

[17] X. Liu, C. Zhang, Z. Geng, and M. Cai, "High-pressure hydrogen storage and optimizing fabrication of corncob-derived activated carbon," Microporous and Mesoporous Materials, vol. 194, pp. 60-65, 2014.

[18] W. Su, L. Zhou, and Y.-P. Zhou, "Preparation of activated carbon with high specific surface area from coconut shell," Chemistry and Industry of Forest Products, vol. 26, no. 2, pp. 49-52, 2006.

[19] P.-H. Huang, J.-W. Jhan, Y.-M. Cheng, and H.-H. Cheng, "Effects of carbonization parameters of Moso-Bamboo-based porous charcoal on capturing carbon dioxide," The Scientific World Journal, vol. 2014, Article ID 937867, 8 pages, 2014.

[20] Chinese National Standards, "Standard test method of ash content for activated carbon,” Tech. Rep. 5581, CNS, 2012.

[21] Chinese National Standards, "Standard test method of $\mathrm{pH}$ value for industrial activated carbon," CNS 697-698, Chinese National Standards, 2012.

[22] American Society for Testing and Materials (ASTM), "Standard test method for determination of iodine number of activated carbon,” Tech. Rep. D-4607-94, American Society for Testing and Materials (ASTM), 2011.

[23] Y. Wang, Y. Hu, X. Zhao, S. Wang, and G. Xing, "Comparisons of biochar properties from wood material and crop residues at different temperatures and residence times," Energy and Fuels, vol. 27, no. 10, pp. 5890-5899, 2013.

[24] G. Afrane and O.-W. Achaw, "Effect of the concentration of inherent mineral elements on the adsorption capacity of coconut shell-based activated carbons," Bioresource Technology, vol. 99, no. 14, pp. 6678-6682, 2008.
[25] K. Raveendran, A. Ganesh, and K. C. Khilar, "Influence of mineral matter on biomass pyrolysis characteristics," Fuel, vol. 74, no. 12, pp. 1812-1822, 1995.

[26] http://www.igcl.com/php/activated_carbon.php.

[27] A. H. Abdullah, A. Kassim, Z. Zainal et al., "Preparation and characterization of activated carbon from gelam wood bark (Melaleuca cajuputi)," The Malaysian Journal of Analytical Sciences, vol. 7, no. 1, pp. 65-68, 2001.

[28] O.-W. Achaw and G. Afrane, "The evolution of the pore structure of coconut shells during the preparation of coconut shell-based activated carbons," Microporous and Mesoporous Materials, vol. 112, no. 1-3, pp. 284-290, 2008.

[29] D. C. S. Azevedoa, J. C. S. Araújoa, M. B. Netoa, A. E. B. Torresa, E. F. Jaguaribeb, and C. L. Cavalcantea, "Microporous activated carbon prepared from coconut shells using chemical activation with zinc chloride," Microporous Mesoporous Mater, vol. 100, pp. 361-364, 2007.

[30] R. A. Hutchins, "Economic factors in granular carbon thermal regeneration," Chemical Engineering Progress, vol. 69, pp. 48-55, 1973.

[31] X. Hu, M. Radosz, K. A. Cychosz, and M. Thommes, " $\mathrm{CO}_{2}$ filling capacity and selectivity of carbon nanopores: synthesis, texture, and pore-size distribution from quenched-solid density functional theory (QSDFT)," Environmental Science and Technology, vol. 45, no. 16, pp. 7068-7074, 2011.

[32] S.-Y. Lee and S.-J. Park, "Determination of the optimal pore size for improved $\mathrm{CO}_{2}$ adsorption in activated carbon fibers," Journal of Colloid and Interface Science, vol. 389, no. 1, pp. 230235, 2013.

[33] A. S. Ello, L. K. C. de Souza, A. Trokourey, and M. Jaroniec, "Coconut shell-based microporous carbons for $\mathrm{CO}_{2}$ capture," Microporous and Mesoporous Materials, vol. 180, pp. 280-283, 2013. 

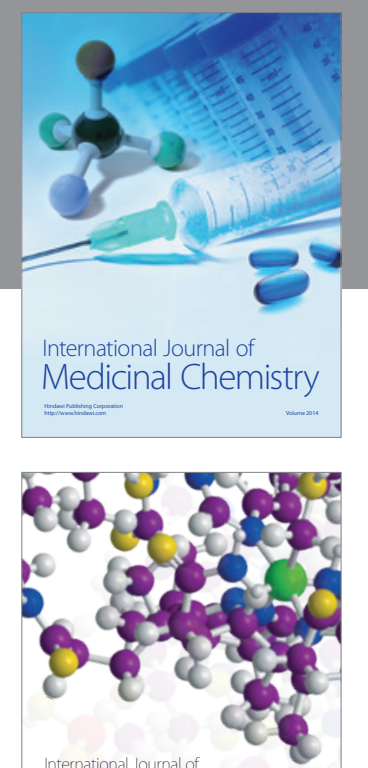

\section{Carbohydrate} Chemistry



The Scientific World Journal
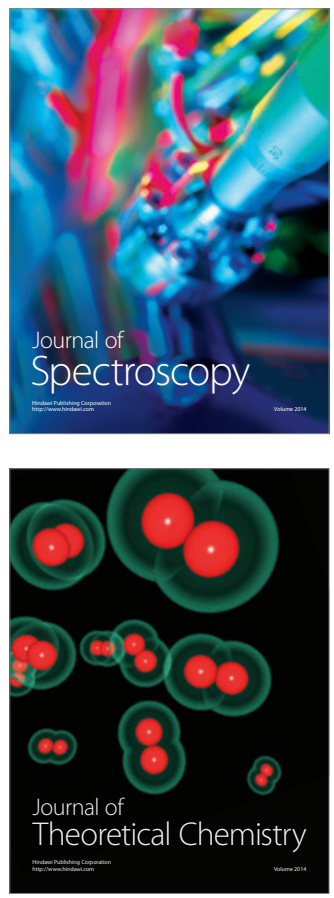
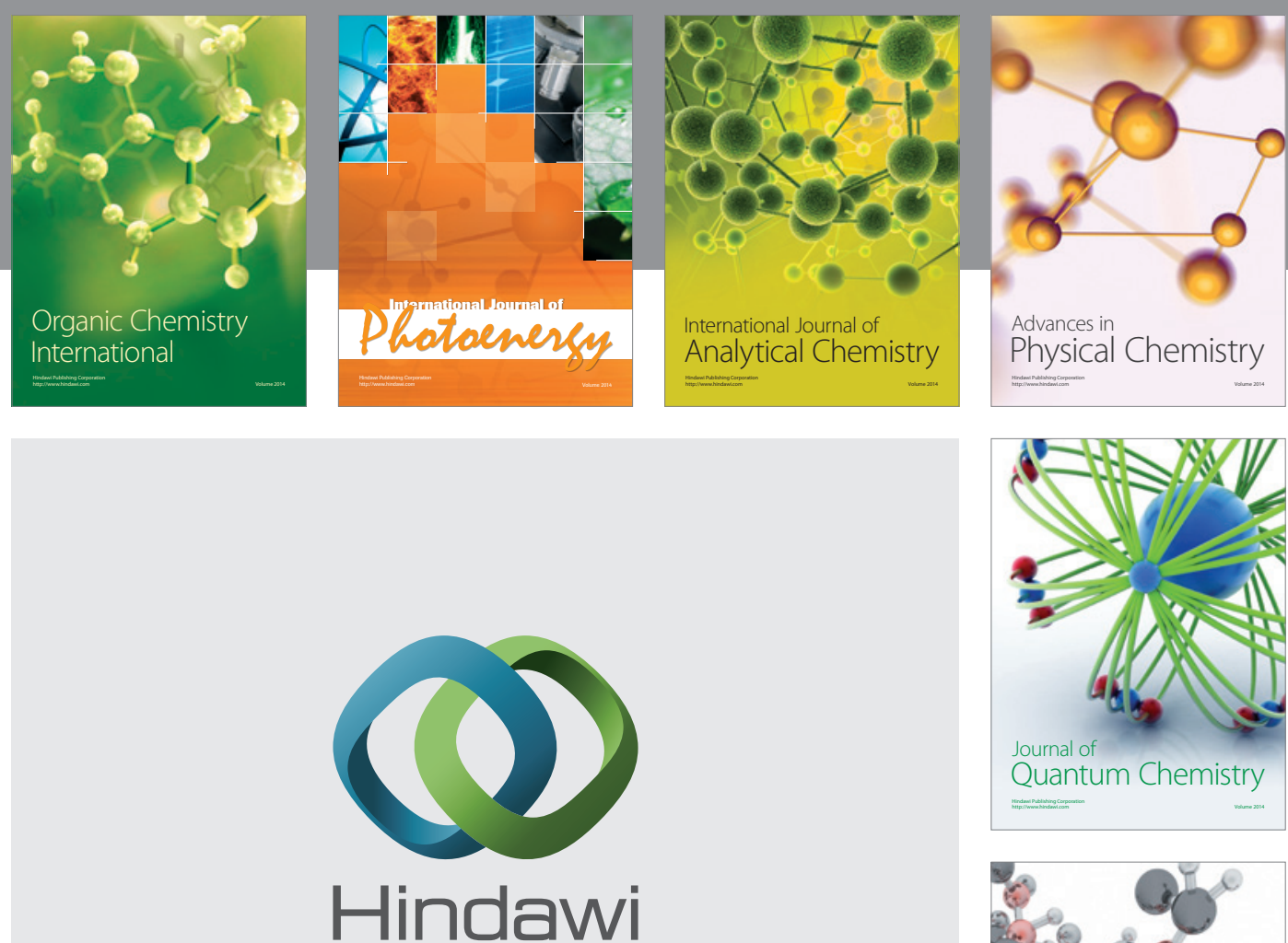

Submit your manuscripts at

http://www.hindawi.com



Analytical Methods

in Chemistry

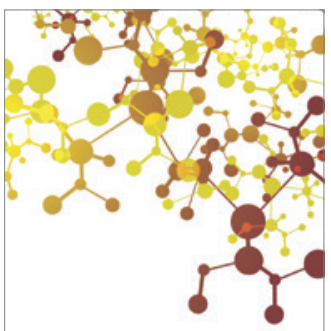

Journal of

Applied Chemistry

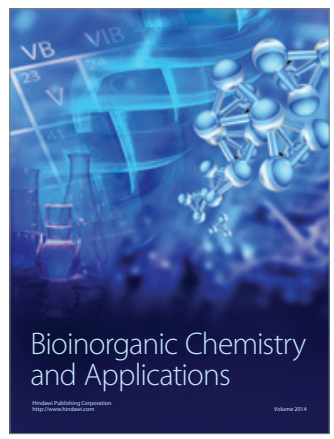

Inorganic Chemistry
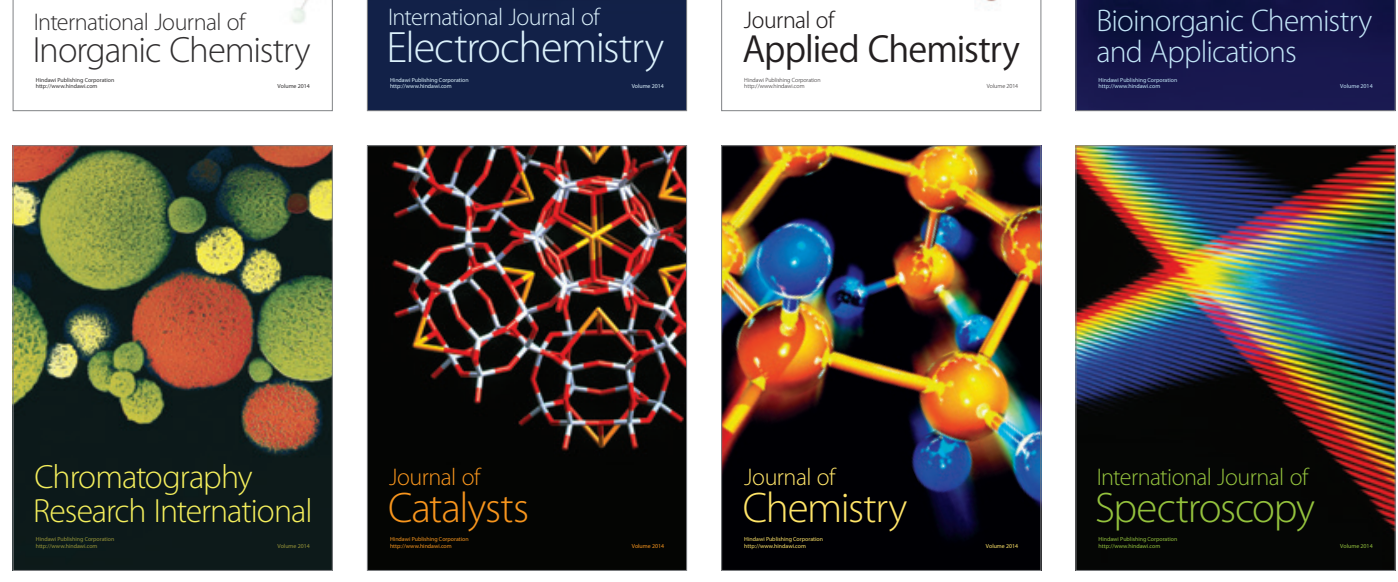